\title{
Serum PCSK9 levels, but not PCSK9 polymorphisms, are associated with CAD risk and lipid profiles in southern Chinese Han population
}

\author{
Gaojun Cai ${ }^{1{ }^{*}}$, Lei Yu ${ }^{1+}$, Zhiying Huang ${ }^{2}, \mathrm{Li} \mathrm{Li}^{1}$ and Xingli Fu${ }^{3^{*}}$
}

\begin{abstract}
Background: Genetic and environment factors affect the occurrence and development of coronary artery disease (CAD). Proprotein convertase subtilisin/kexin type 9 (PCSK9), has been investigated extensively in the field of lipid metabolism and CAD. We performed this case-control study to investigate the relationship between serum PCSK9 levels and PCSK9 polymorphisms and lipid levels and CAD risk in a southern Chinese population.
\end{abstract}

Methods: A hospital-based case-control study with 1, 096 subjects, including 626 CAD patients and 470 controls, were conducted. Genotyping of PCSK9 polymorphisms was performed using polymerase chain reaction-ligase detection reaction (PCR-LDR) method.

Results: The frequencies of the AA, AG and GG genotypes of PCSK9 E670G polymorphism were 90.58, 9.27, and $0.16 \%$ in the CAD patients, compared with $88.72,10.85$ and $0.43 \%$ in the controls, respectively. No R46L variant was detected in this population. There were no significant differences in genotype and allele frequencies of PCSK9E670G polymorphism between the CAD group and the controls. Serum lipid levels were not significantly different in carriers with the G allele and those with the AA genotype. The median (QR) of PCSK9 concentration was 1205. $00 \mathrm{ng} / \mathrm{l}(577.28-1694.13 \mathrm{ng} / \mathrm{l})$ in cases and $565.87 \mathrm{ng} / \mathrm{l}(357.17-967.50 \mathrm{ng} / \mathrm{l})$ in controls, respectively. Compared with controls, CAD patients had significantly higher PCSK9 levels $(z=4.559, P<0.001)$. After adjusting for age, gender, essential hypertension, diabetic mellitus, smoking and lipid profiles, PCSK9 levels remain significantly associated with increased CAD susceptibility $(\mathrm{OR}=1.002,95 \% \mathrm{Cl}=1.001-1.002, P<0.001)$. The correlation analyses showed that serum PCSK9 levels were positively associated with triglyceride (TG), Apo B and atherogenic index of plasma (AIP) levels in controls. No significant association between the PCSK9 E670G polymorphism and serum PCSK9 levels was observed in the CAD group and the controls.

Conclusions: The present study shows that serum PCSK9 levels, but not PCSK9 polymorphisms, are associated with CAD risk in Southern Chinese Han population, and that serum PCSK9 levels are positively associated with AIP.

Keywords: Lipids, Dyslipidaemia, Coronary artery disease, Gene, Polymorphism, Atherogenic index of plasma

\footnotetext{
* Correspondence: cgj982@126.com; henry.f@163.com

${ }^{\dagger}$ Gaojun Cai and Lei Yu contributed equally to this work.

${ }^{1}$ Department of Cardiology, WujinHospital affiliated with Jiangsu University,

Changzhou, Jiangsu Province 213017, China

${ }^{3}$ Jiangsu University Health Science Center, Zhenjiang, Jiangsu Province

212001, China

Full list of author information is available at the end of the article
}

(c) The Author(s). 2018 Open Access This article is distributed under the terms of the Creative Commons Attribution 4.0 International License (http://creativecommons.org/licenses/by/4.0/), which permits unrestricted use, distribution, and reproduction in any medium, provided you give appropriate credit to the original author(s) and the source, provide a link to the Creative Commons license, and indicate if changes were made. The Creative Commons Public Domain Dedication waiver (http://creativecommons.org/publicdomain/zero/1.0/) applies to the data made available in this article, unless otherwise stated. 


\section{Background}

Coronary artery disease (CAD), which is characterized as multi-factor disease remains the leading cause of morbidity and mortality worldwide [1]. Genetic and environmental factors affect the occurrence and development of CAD. Numerous epidemiological and clinical studies have shown that dyslipidemia, including the high low-density lipoprotein cholesterol (LDL-C) and low high-density lipoprotein cholesterol (HDL-C) levels, is strongly associated with an increased risk of CAD [2]. Atherogenic index of plasma (AIP), a new comprehensive lipid index, comprehensively reflects the balance between atherogenic and anti-atherogenic factors, and is a stronger and independent risk factor for CAD $[3,4]$.

Proprotein convertase subtilisin/kexin type 9 (PCSK9), the ninth member of the proprotein convertase family, has been investigated extensively in the field of lipid metabolism [5]. By combining with the epidermal growth factor-like repeat A domain (EGF-A) of low-density lipoprotein receptor (LDLR) and lowing the recycling of LDLR to cell surface, PCSK9 mediates serum LDL-C levels. Recently, several PCSK9 inhibitors, such as alirocumab and evolocumab, were applied in patients with familial hypercholesterolemia and/or CAD in different countries, and were verified to decrease total cholesterol (TC), LDL-C, triglyceride (TG) and the ratio of TC to high-density lipoprotein cholesterol (HDL-C) greatly [6].

PCSK9 gene is located on chromosome 1p32.3 and encompasses 12 exons. Until now, approximately 160 mutations in PCSK9 gene have been investigated. According to their effects on LDLR, PCSK9 gene mutations are divided into loss-of-function (LOF) and gain-of-function (GOF) mutations. LOF mutations in the PCSK 9 gene decrease LDLR degradation, thereby reducing serum LDL-C levels and the risk of CAD. Conversely, GOF mutations may increase serum LDL-C levels and CAD risk. PCSK9 E670G polymorphism (rs505151) is a common variant and is a GOF mutation, while R46L (rs11591147) is a rare variant and belongs to the LOF mutations. Several studies have investigated the relationships between these two variants and lipid levels and CAD susceptibility in different populations. However, the results were inconsistent. In 2015 and 2017, three meta-analyses were carried out to clarify the association between PCSK9 E670G polymorphism and lipid levels and the risk of CAD [7-9]. Although pooled effects indicated that $\mathrm{G}$ allele carriers had a higher risk of CAD and LDL-C levels than non-carriers, the heterogeneity among the studies was statistically significant, suggested that the results should be interpreted cautiously. Additionally, the relationships between the E670G polymorphism and other lipid profiles remained inconsistent. A study with a large sample size is needed to verify the results. Data from previous studies indicated that the variant of R46L is rare in both Caucasians and Asians [10, 11]. Caucasians carriers of the minor allele had lower cardiovascular disease susceptibility and lower LDL-C levels [9]. However, no study has been conducted on the relationship between the PCSK9 R46L polymorphism and lipid levels and cardiovascular risk in a Chinese population. Moreover, no study has been designed to explore the relationship between PCSK9 and the comprehensive lipid index. Therefore, we carried out a hospital-based case-control study with 1, 096 subjects to investigate the relationship between PCSK9 polymorphisms and lipid levels and CAD risk in a Southern Chinese population.

\section{Methods}

\section{Subjects}

The present retrospective case-control study included 1, 096 participants. All participants were Han Chinese and underwent coronary angiography (CAG) examination in the Department of Cardiology inWujin hospital affiliated to Jiangsu University between September 2012 and July 2017. Total of 626 CAD patients, including 364 myocardial infarction, 226 unstable angina pectoris and 36 stable angina pectoris involved in our study. The diagnosis of CAD was described in our previous study [12], which was in line with the World Health Organization criteria from 1978. The controls also underwent CAG examination in the same period and had a luminal stenosis of $<50 \%$ of the major coronary arteries. Judikin's method was used in the CAG examination and the images were evaluated by two experienced cardiologists. Patients with advanced liver or kidney failure, malignant tumors, asthma and major surgery or trauma within one month were excluded. Patients currently using lipid-lowing drugs were also excluded in the present study. Informed consent was obtained from all participants. The study was approved by the ethics committee of Wujin hospital.

\section{Biochemical parameter analysis}

Approximately $2 \mathrm{ml}$ of venous blood was extracted from each participant after $12 \mathrm{~h}$ fasting. The methods to measure biochemical parameters were performed as previously described [13]. All of the biochemical parameters, including TC, TG, HDL-C, LDL-C, ApoA1, ApoB, $\mathrm{Lp}(\mathrm{a})$ and glucose levels, were analyzed by automatic biochemical analyzer (Olympus AU5400). AIP is calculated as $\log _{10}$ (TG/HDL-C).

\section{Genotyping of PCSK9 polymorphisms}

Total genomic DNA was extracted from peripheral blood leukocytes. The method of extraction was described in previous study [13]. Genotyping of PCSK9 polymorphisms was performed using polymerase chain 
reaction-ligase detection reaction (PCR-LDR) method. The sequences of primers and probes are listed in Additional file 1: Table S1. PCR was performed with a volume of $25 \mu \mathrm{l}$ reaction system, including $1 \mu \mathrm{l}$ genomic

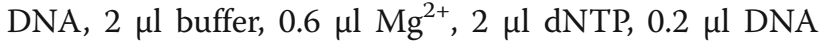
polymerase, and $2 \mu \mathrm{l}$ Primer mix. Multiplex PCR reaction was carried out by an initial denaturation at $95{ }^{\circ} \mathrm{C}$ for $2 \mathrm{~min}$, followed by 40 cycles at $94{ }^{\circ} \mathrm{C}$ for $90 \mathrm{~s}, 53^{\circ} \mathrm{C}$ for $1.5 \mathrm{~min}, 65^{\circ} \mathrm{C}$ for $30 \mathrm{~s}$, and a terminal extension $65^{\circ} \mathrm{C}$ for $10 \mathrm{~min}$. After PCR amplification, the LDR was carried out with a volume of $10 \mu \mathrm{l}$ reaction system, including $4 \mu \mathrm{l}$ PCR product, $1 \mu \mathrm{l}$ buffer, $1 \mu \mathrm{l}$ Probe mix, $0.05 \mu \mathrm{l}$ Taq DNA ligase, and $4 \mu \mathrm{lddH_{2 }}$ O with a produce of 40 cycles of pre-denaturation at $95{ }^{\circ} \mathrm{C}$ for $2 \mathrm{~min}$, annealing at $94{ }^{\circ} \mathrm{C}$ for $15 \mathrm{~s}$, and extension at $50{ }^{\circ} \mathrm{C}$ for $25 \mathrm{~s}$. The genotypes were analyzed by ABI PRISM 3730 sequencer and Genemapper software. The results of genemapper analyses are shown in Additional file 2: Figure S1.

\section{Statistical analysis}

All data were analysed using SPSS 17.0 software package (SPSS Inc., Chicago, Illinois). The Hardy-Weinberg equilibrium (HWE) was assessed using the goodness-of-fit method. The Kolmogorov-Smirnov test was used to examine the normality of the distributions of continuous variables. For continuous variables that satisfied normal distribution, the data were expressed as the means \pm standard deviation (SD) and were compared using independent-sample $\mathrm{t}$-tests. Otherwise, the data were expressed as medians and quartile ranges (QR), and were compared using the Mann-Whitney test. Qualitative variables were assessed using the Chi- square test.The association between the genotypes and CAD risk was evaluated by calculating the values of the crude odds ratios (ORs), together with 95\% confidence intervals (CIs) and adjusted ORs. Correlation analysis was performed using the Pearson test. A two-sided $p$-value of $<0.05$ was regarded as significant.

\section{Results}

\section{Characteristics of the involved participants}

In total, 1, 096 subjects, including $626 \mathrm{CAD}$ patients (439 males and 187 females; mean age, $64.18 \pm 9.83$ years) and 470 controls (243 males and 227 females; mean age, $61.62 \pm 9.42$ years), were enrolled in the study. As shown in Table 1, CAD patients were older than controls $(P<0.01)$. The frequencies of male gender, essential hypertension $(\mathrm{EH})$, diabetes mellitus (DM) and smoking were significantly higher in the CAD patients than in the controls. In addition, the patients with CAD had higher TC, LDL-C and Apo B levels when compared with the control subjects. On the other hand, the levels of HDL-C and Apo A1 were significantly lower in the CAD patients than in the
Table 1 The characteristics of CAD patients and controls

\begin{tabular}{lllll}
\hline Characteristics & CAD $(n=626)$ & Controls $(n=470)$ & $X^{2}(t)$ & $P$ \\
\hline Age (years) & $64.18 \pm 9.83$ & $61.62 \pm 9.42$ & 4.337 & $<0.01$ \\
Male $[n(\%)]$ & $439(70.13)$ & $243(51.70)$ & 38.774 & $<0.01$ \\
EH [n (\%)] & $454(72.52)$ & $276(58.72)$ & 22.986 & $<0.01$ \\
DM [n (\%)] & $163(26.04)$ & $67(14.26)$ & 22.478 & $<0.01$ \\
Smoking [n (\%)] & $239(38.18)$ & $114(24.26)$ & 23.835 & $<0.01$ \\
TC (mmol/l) & $4.59 \pm 1.05$ & $4.42 \pm 0.96$ & 2.807 & $<0.01$ \\
TG (mmol/l) & $1.84 \pm 1.50$ & $1.76 \pm 1.46$ & 0.949 & $>0.05$ \\
HDL-C (mmol/l) & $1.08 \pm 0.27$ & $1.16 \pm 0.31$ & 4.752 & $<0.01$ \\
LDL-C (mmol/l) & $2.93 \pm 0.92$ & $2.64 \pm 0.79$ & 5.572 & $<0.01$ \\
ApoA1 (g/l) & $1.18 \pm 0.23$ & $1.23 \pm 0.24$ & 3.691 & $<0.01$ \\
ApoB (g/l) & $1.16 \pm 0.31$ & $1.08 \pm 0.27$ & 3.789 & $<0.01$ \\
\hline CAD cor &
\end{tabular}

CAD coronary artery disease, TC total cholesterol, TG triglyceride, HDL-C highdensity lipoprotein cholesterol, LDL-C low-density lipoprotein cholesterol, $E H$ essential hypertension, $D M$ diabetes mellitus

controls. In addition, there were no significant difference in TG levels between the CAD patients and the controls.

\section{Association between the PCSK9 polymorphisms and CAD risk}

Table 2 shows that the genotype and allele frequencies of PCSK9 E670G in the cases and controls. The genotype frequency in the controls was in accordance with HWE $(P>0.05)$. The frequencies of the AA, AG and GG genotypes were $90.58,9.27$ and $0.16 \%$ in the CAD group, compared with $88.72,10.85$ and $0.43 \%$ in the controls, respectively. The $G$ allele frequency was $4.79 \%$ in the CAD group and $5.85 \%$ in the controls. There were no significant differences in genotype and allele frequencies between the CAD group and controls. Because the GG genotype was minor, AG and GG genotypes were grouped into the carriers of $G$ allele (AG + GG). Crude OR with 95\% CI and adjusted OR with $95 \% \mathrm{CI}$ both indicated that carriers with $\mathrm{G}$ allele had not significant difference in the risk of CAD compared with carriers with AA genotype. Further subgroup analyses stratified by gender, age, EH and DM were carried out. No significant differences were found between

Table 2 Distribution in the genotype and allele frequencies of PCSK9 E670G in CAD and control groups

\begin{tabular}{lllll}
\hline Genotype/Allele & CAD $[n(\%)]$ & Controls $[n(\%)]$ & $x^{2}$ & $P$ \\
\hline AA & $567(90.58)$ & $417(88.72)$ & 1.474 & 0.478 \\
AG & $58(9.27)$ & $51(10.85)$ & & \\
GG & $1(0.16)$ & $2(0.43)$ & & \\
A & $1192(95.21)$ & $885(94.15)$ & 1.211 & 0.288 \\
G & $60(4.79)$ & $55(5.85)$ & & \\
\hline
\end{tabular}

CAD coronary artery disease 
the E670G polymorphism and CAD susceptibility in any subgroups (Table 3).

In addition, only GG genotype in R46L variant was detected in this population.

\section{Association between the PCSK9 E670G polymorphism and lipid levels}

The relationship between the PCSK9 E670G polymorphism and lipid levels was also investigated. As shown in Table 4, serum lipid levels were not significantly different in carriers with $\mathrm{G}$ allele and those with AA genotype. Subgroup analyses based on age and gender did not find the association of the PCSK9 E670G polymorphism with lipid profiles (Data were not listed).

\section{Associations between serum PCSK9 levels and CAD risk and lipid levels}

144 subjects (72 cases and 72 controls) were selected to detect the serum PCSK9 level. There were no significant differences in age (CAD, age 65.26 \pm 10.22 years; controls, age $62.47 \pm 8.49$ years, $P>0.05)$ and gender (CAD, male 68.06\%; controls, male 58.33\%, $P>0.05$ ) between
CAD and control groups. The median (QR) of PCSK9 concentration was $1205.00 \mathrm{ng} / \mathrm{l}(577.28-1694.13 \mathrm{ng} / \mathrm{l}) \mathrm{in}$ cases and $565.87 \mathrm{ng} / \mathrm{l}(357.17-967.50 \mathrm{ng} / \mathrm{l})$ in controls, respectively. Compared with controls, CAD patients had significantly higher PCSK9 levels $(\mathrm{z}=4.559, P<0.001)$ (Fig. 1). After adjusting with age, gender, EH, DM, smoking and lipid profiles, PCSK9 levels remain significantly associated with increased CAD susceptibility $(\mathrm{OR}=1.002,95 \% \mathrm{CI}=1.001-1.002, P<0.001)$. The correlation analyses showed that serum PCSK9 levels were positively associated with TG, Apo B and AIP levels in the controls (Fig. 2, Table 5).

\section{Association between PCSK9 E670G polymorphism and PCSK9 levels}

No significant association between PCSK9 E670G polymorphism and PCSK9 levels was observed in CAD group and control group. Subgroup analyses based on age, gender, EH and DM status revealed that PCSK9 E670G polymorphism was not associated with PCSK9 levels (Additional file 3: Figure S2).

Table 3 Association of PCSK9 E670G polymorphism and CAD risk

\begin{tabular}{|c|c|c|c|c|c|c|c|c|}
\hline & & & CAD (n) & Controls (n) & Crude OR (95\% CI) & $P$ & Adjusted OR (95\% Cl) & $p^{@}$ \\
\hline \multirow[t]{2}{*}{ All } & & AA & 567 & 417 & $0.819(0.553-1.212)$ & 0.317 & $0.838(0.548-1.280)$ & 0.414 \\
\hline & & $A G+G G$ & 59 & 53 & & & & \\
\hline \multirow[t]{4}{*}{ Gender } & Male & AA & 396 & 220 & $0.960(0.564-1.636)$ & 0.882 & $0.952(0.541-1.675)$ & 0.864 \\
\hline & & $A G+G G$ & 43 & 23 & & & & \\
\hline & Female & AA & 171 & 197 & $1.636(0.862-3.104)$ & 0.132 & $0.706(0.345-1.445)$ & 0.341 \\
\hline & & $A G+G G$ & 16 & 30 & & & & \\
\hline \multirow[t]{4}{*}{ Age } & $\geq 60$ (years) & AA & 407 & 268 & $0.850(0.530-1.365)$ & 0.501 & $0.790(0.363-1.509)$ & 0.407 \\
\hline & & $A G+G G$ & 44 & 34 & & & & \\
\hline & $<60$ (years) & AA & 159 & 149 & $0.740(0.363-1.509)$ & 0.407 & $0.896(0.408-1.970)$ & 0.785 \\
\hline & & $A G+G G$ & 15 & 19 & & & & \\
\hline \multirow[t]{4}{*}{ EH } & Yes & AA & 415 & 244 & $0.717(0.437-1.174)$ & 0.186 & $0.688(0.406-1.165)$ & 0.164 \\
\hline & & $A G+G G$ & 39 & 32 & & & & \\
\hline & No & AA & 152 & 173 & $1.084(0.566-2.076)$ & 0.808 & $1.260(0.586-2.709)$ & 0.554 \\
\hline & & $A G+G G$ & 20 & 21 & & & & \\
\hline \multirow[t]{4}{*}{ DM } & Yes & AA & 149 & 57 & $0.946(0.583-1.532)$ & 0.820 & $0.497(0.193-1.278)$ & 0.147 \\
\hline & & $A G+G G$ & 14 & 10 & & & & \\
\hline & No & $A A$ & 418 & 360 & $0.901(0.580-1.401)$ & 0.644 & $0.536(0.225-1.275)$ & 0.158 \\
\hline & & $A G+G G$ & 45 & 43 & & & & \\
\hline \multirow[t]{4}{*}{ Smoking } & Yes & AA & 219 & 105 & $1.065(0.469-2.420)$ & 0.880 & $1.055(0.443-2.512)$ & 0.903 \\
\hline & & $A G+G G$ & 20 & 9 & & & & \\
\hline & No & $\mathrm{AA}$ & 348 & 312 & $0.795(0.503-1.255)$ & 0.325 & $0.834(0.498-1.397)$ & 0.490 \\
\hline & & $A G+G G$ & 39 & 44 & & & & \\
\hline
\end{tabular}


Table 4 Association between PCSK9 E670G polymorphism and lipid levels

\begin{tabular}{lllllllll}
\hline & & TC $(\mathrm{mmol} / \mathrm{l})$ & $\mathrm{TG}(\mathrm{mmol} / \mathrm{l})$ & $\mathrm{HDL}-\mathrm{C}(\mathrm{mmol} / \mathrm{l})$ & LDL-C $(\mathrm{mmol} / \mathrm{l})$ & Apo A1 $(\mathrm{g} / \mathrm{l})$ & Apo B $(\mathrm{g} / \mathrm{l})$ & AIP \\
\hline CAD & AA & $4.59 \pm 1.06$ & $1.85 \pm 1.53$ & $1.08 \pm 0.27$ & $2.93 \pm 0.93$ & $1.18 \pm 0.23$ & $0.97 \pm 0.30$ & $0.15 \pm 0.28$ \\
& $\mathrm{AG}+\mathrm{GG}$ & $4.64 \pm 0.94$ & $1.77 \pm 1.15$ & $1.07 \pm 0.22$ & $3.01 \pm 0.78$ & $1.19 \pm 0.21$ & $0.99 \pm 0.26$ & $0.05 \pm 0.24$ \\
& $P$ & 0.565 & 0.876 & 0.798 & 0.462 & 0.574 & 0.457 & 0.339 \\
Controls & AA & $4.41 \pm 0.97$ & $1.77 \pm 1.51$ & $1.16 \pm 0.30$ & $2.64 \pm 0.80$ & $1.23 \pm 0.24$ & $0.91 \pm 0.26$ & $0.09 \pm 0.34$ \\
& AG $+\mathrm{GG}$ & $4.46 \pm 0.90$ & $1.63 \pm 1.02$ & $1.17 \pm 0.34$ & $2.67 \pm 0.74$ & $1.23 \pm 0.24$ & $0.90 \pm 0.27$ & $0.08 \pm 0.36$ \\
& $P$ & 0.831 & 0.482 & 0.823 & 0.822 & 0.929 & 0.912 & 0.937 \\
\hline
\end{tabular}

$C A D$ coronary artery disease, $T C$ total cholesterol, $T G$ triglyceride, $H D L-C$ high-density lipoprotein cholesterol, $L D L-C$ low-density lipoprotein cholesterol, $A I P$ atherogenic index of plasma

\section{Discussion}

PCSK9, originally named neural apoptosis regulated convertase-1 (NARC-1), is mainly expressed in the liver, kidney and intestine. In recent years, the associations between PCSK9 and the metabolism of LDL-C and the risk of CAD have been investigated extensively [5]. LDLR plays a crucial role in the metabolism of LDL-C in vitro and in vivo. In general, when LDL is combined with LDLR, it is internalized into clathrin-coated pits and subsequently degraded in the lysosome. LDLR is then recycled to the cell surface. PCSK9 increases the circulation unfriendly lipoprotein cholesterol by mediating the degradation and recirculation of several lipoprotein receptors, such as LDLR and VLDLR, via the EGF-A-binding domain. The inhibition of PSCK9 reduces LDL-C levels greatly, even in patients with statin ineffectiveness or intolerance [14], which has been seemed as a novel target for decreasing plasma lipid levels. Recent studies have indicated that PCSK9 increases the risk of CAD and is positively associated with CAD severity $[15,16]$. In addition, circulating PCSK9 might independently predict the future risk of cardiovascular events [17]. The results of the present study indicated that PCSK9 levels were significantly higher in the CAD group than in the controls, which was consistent with previous reports describing the association between PCSK9 and the risk of CAD [5]. After adjusting for age, gender, EH, DM, smoking and lipid levels, PCSK9 levels remained an independent risk factor for CAD. The correlation analysis of PCSK9 and lipid profiles showed that PCSK9 levels were positively associated with TG and Apo B levels in the controls. Interestingly, PCSK9 levels were also positively associated with AIP, which was reported for the first time. Previous studies revealed that AIP, which represents the logarithm of the molar ratio of TG to HDL-C, was inversely associated with the diameter of LDL-C particles and indicated sdLDL

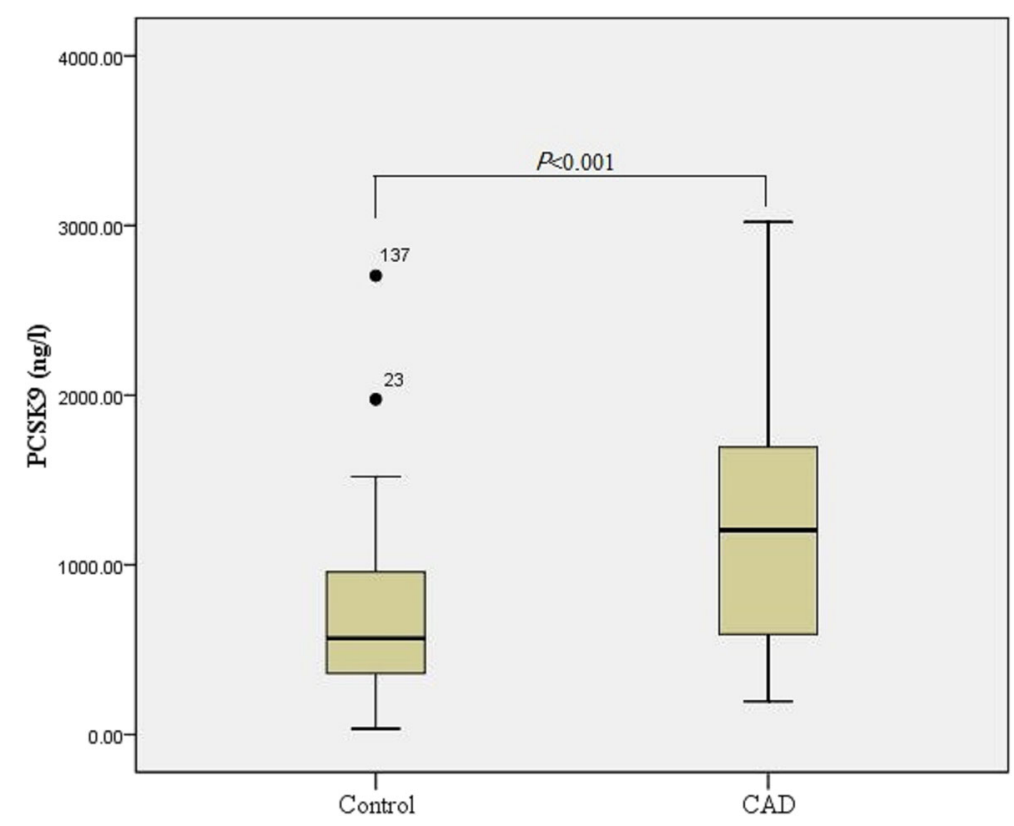

Fig. 1 Serum PCSK9 levels in CAD and control groups 

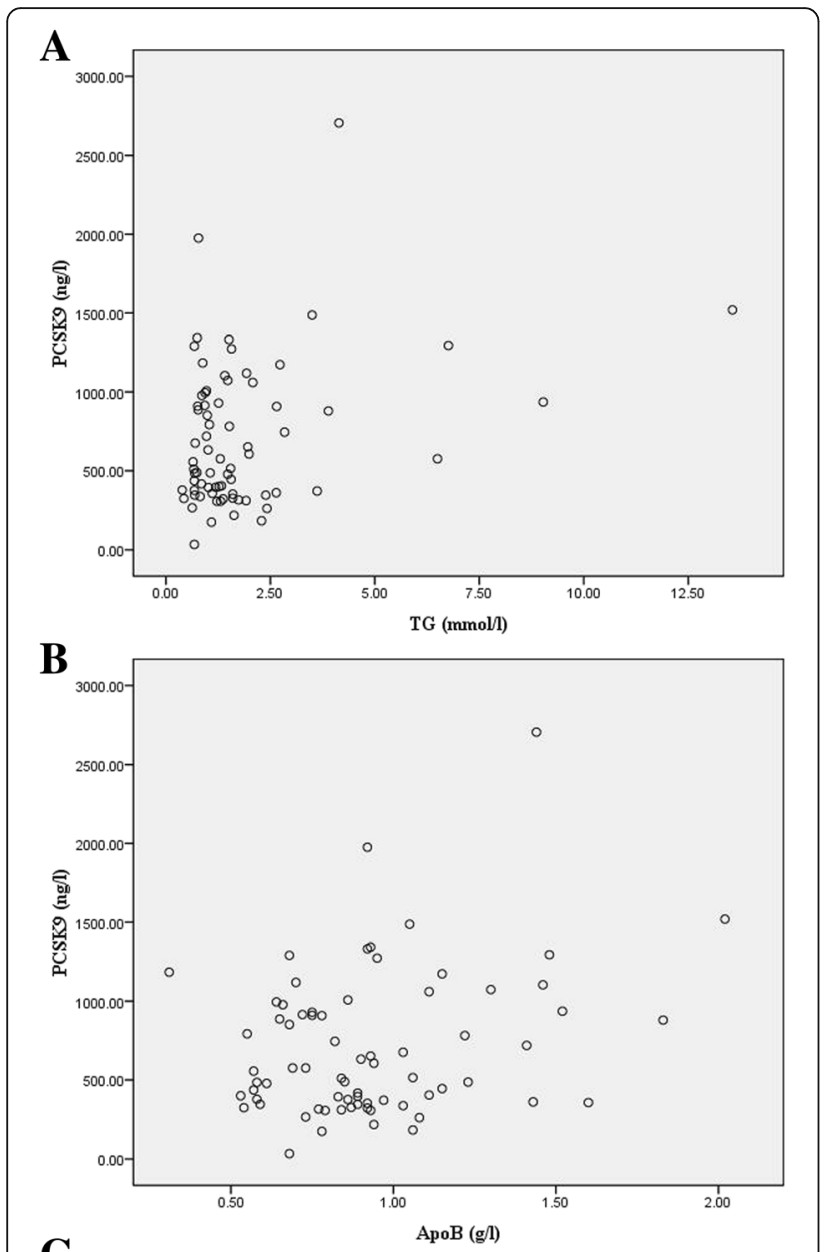

$\mathrm{C}$

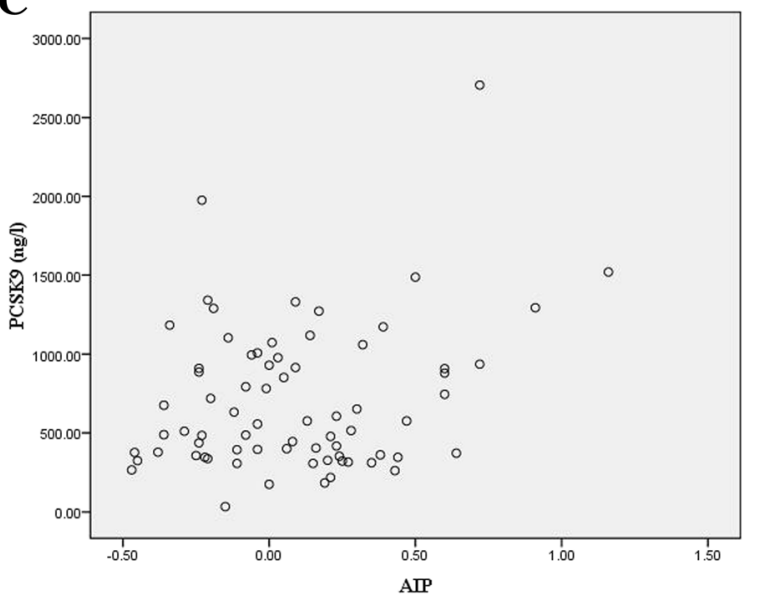

Fig. 2 Correlation between PCSK9 levels and lipid profiles (a TG; b ApoB; c AIP)

particle size [18]. An increase of PCSK9 may predict a decrease in lipoprotein particle size, and this may partly explain the pro-atherosclerotic mechanisms of PCK9. After PCSK9 inhibition, the size of the LDL and VLDL particles increased, and the concentrations of LDL-C and total LDL particles were reduced, corroborating this speculation [19].

Previous studies have indicated that the PCSK9 E670G polymorphism might be associated with lipid levels and the risk and severity of CAD [7]. This variant leads to a change from $\mathrm{E}$ to $\mathrm{G}$ at position 670 of the PCSK9 protein, and this may increase the affinity of PCSK9 for the LDLR. In the Strong Heart Family Study, a family-based genetic study, the authors found that E670G polymorphism was significantly associated with LDL-C levels in 2458 American Indians [20]. In Tunisian cohort, the 670G carriers had significantly higher TC and LDL-C levels compared to E670 carriers in CAD patients. In addition, the risk and severity of CAD were significantly increased in 670G carriers [21]. However, studies in different ethnic groups had controversial results [11, 22]. Even in the same ethnic population, the results were inconsistent, suggesting that region might affect the distribution of genotypes [23, 24]. Hsu LA et al. concluded that the PCSK9 gene E670G polymorphism was not a risk factor for CAD, although it affects LDL-C levels [24]. However, Zhang $\mathrm{N}$ et al. revealed that carriers of the $\mathrm{G}$ allele had a higher risk of CAD than those with the A allele, and those with the $\mathrm{G}$ allele had higher TC and TG levels than those with the AA genotype in a Chinese population [25]. In the present study, only three subjects with the GG genotype were detected. The frequency of the minor allele was $5.25 \%$ in the whole population, consistent with the findings of Hsu LA et al. [24] and lower than those reported by Zhang $\mathrm{N}$, et al. [25]. The findings of our study suggest that the PCSK9 E670G polymorphism is neither associated with CAD susceptibility nor lipid profiles in the Southern Chinese Han population. Furthermore, subgroup analyses did not find any associations between the E670G polymorphism and CAD risk and lipid levels. The discrepancies of the associations between the PCSK9 E670G polymorphism and the risk of CAD and lipid profiles among various populations may partly be due to the different characteristics of the studied populations, such as diagnostic criteria of CAD, ethnicity, region, and/or environmental factors. In 2013, Aung LH et al. found that the effects of the PCSK9 E670G polymorphism on lipid profiles could be modified by alcohol consumption [26]. In the present study, we first investigated the relationship between the PCSK9 E670G polymorphism and PCSK9 levels in the Chinese population, but no significant association was found. In addition, no PCSK9 R46L polymorphism variant was detected in this Chinese population.

There were several limitations in this study. Firstly, age and gender between cases and controls were not matched, which might lead to the potential selection. Logistic analysis was used to reduce the bias as far as possible. Secondly, the present study was a hospital based 
Table 5 Correlation analyses between PCSK9 levels and lipid profiles

\begin{tabular}{lllllllll}
\hline & & TC & TG & HDL-C & LDL-C & Apo A1 & ApoB & AIP \\
\hline Controls & $r$ & 0.13 & 0.32 & -0.03 & 0.03 & 0.24 & 0.28 & 0.26 \\
& $P$ & 0.28 & 0.01 & 0.80 & 0.83 & 0.05 & 0.02 & 0.03 \\
CAD & $r$ & 0.07 & -0.06 & 0.03 & 0.11 & -0.01 & 0.02 & -0.02 \\
& $P$ & 0.59 & 0.63 & 0.82 & 0.37 & 0.95 & 0.85 & 0.87 \\
\hline
\end{tabular}

CAD coronary artery disease, $T C$ total cholesterol, $T G$ triglyceride, $H D L-C$ high-density lipoprotein cholesterol, $L D L-C$ low-density lipoprotein cholesterol, $A I P$ atherogenic index of plasma

case-control study, which may not be representative of the general population. Finally, the gene-environment interactions might affect the results. Environmental factors such as drinking status and degree of education therefore, might have influenced our results, which were not explored in our study.

\section{Conclusions}

Despite its limitations, the present study shows that serum PCSK9 levels, but not PCSK9 polymorphisms, are associated with the risk of CAD in Southern Chinese Han populations, and that serum PCSK9 levels are positively associated with AIP.

\section{Additional files}

Additional file 1: Table S1. The sequence of PCR primers. Table S2. The sequence of probes used in the study. (DOCX $16 \mathrm{~kb}$ )

Additional file 2: Figure S1. The genemapper analyses of genotypes of PCSK9 polymorphisms (A. E670G AA genotype; B. E670G AG genotype; C. E670G GG genotype; D. R46L GG genotype). (ZIP 7 kb)

Additional file 3: Figure S2. Associations between PCSK9 E670G polymorphism and PCSK9 levels (A. in whole population; B. in case and controls subgroups; $C$. in male and female subgroups; D. in elderly and non-elderly subgroups; E. in $\mathrm{EH}$ and non-EH subgroups; F. in DM and non-DM subgroups). (ZIP $67 \mathrm{~kb}$ )

\section{Abbreviations}

AIP: Atherogenic index of plasma; CAD: Coronary artery disease; CAG: Coronary angiography; DM: Diabetes mellitus; EH: Essential hypertension; HDL-C: Highdensity lipoprotein cholesterol; LDL-C: low-density lipoprotein cholesterol; PCSK9: Proprotein convertase subtilisin/kexin type 9; TC: Total cholesterol; TG: Triglyceride

\section{Acknowledgements}

We thank all our colleagues at the Department of Cardiology, Wujin Hospital, affiliated with Jiangsu University.

\section{Ethical approval and consent to participate}

This study was performed in accordance with the Declaration of Helsinki and approved by the Ethics Committee of Jiangsu University. All participants signed an informed consent.

\section{Funding}

This study was supported by the Jiangsu Youth Medical Talents Project (QNRC2016310), Changzhou Science and Technology Development (CJ20160004), and the Science and Technology Project of Wujin (WS201603).

\section{Availability of data and materials}

The datasets used and/or analyzed during the current study are available from the corresponding author on reasonable request.
Authors' contributions

All authors have read the manuscript and agreed with the contents. GC and XF conceived and designed the experiments; GC, LY and LL performed the experiments; GC and LY analyzed the data; GC contributed reagents/ materials/analysis tools; GC and ZH wrote the paper.

\section{Consent for publication}

Not applicable.

\section{Competing interests}

The authors declare that they have no competing interests.

\section{Publisher's Note}

Springer Nature remains neutral with regard to jurisdictional claims in published maps and institutional affiliations.

\section{Author details}

${ }^{1}$ Department of Cardiology, WujinHospital affiliated with Jiangsu University, Changzhou, Jiangsu Province 213017, China. ${ }^{2}$ Department of Pediatrics, No. 2 Hospital of Changzhou, Changzhou 213001, Jiangsu, China. ${ }^{3}$ Jiangsu University Health Science Center, Zhenjiang, Jiangsu Province 212001, China.

Received: 28 June 2018 Accepted: 28 August 2018

Published online: 11 September 2018

\section{References}

1. Gasior M, Gierlotka M, Pyka Ł, Zdrojewski T, Wojtyniak B, Chlebus K, Rozentryt P, Niedziela J, Jankowski P, Nessler J, Opolski G, Hoffman P, Jankowska E, Polonski L, Ponikowski P Temporal trends in secondary prevention in myocardial infarction patients discharged with left ventricular systolic dysfunction in Poland. Eur J Prev Cardiol 2018; 1:2047487318770830. [PMID: 29692221]

2. Li WJ, Yin RX, Cao XL, Chen WX, Huang F, Wu JZ. DOCK7-ANGPTL3 SNPs and their haplotypes with serum lipid levels and the risk of Coron Artery Dis and ischemic stroke. Lipids Health Dis 2018, 17(1):30. https://doi.org/10. 1186/s12944-018-0677-9. [PMID:29454388].

3. Cai G, Shi G, Xue S, Lu W.The atherogenic index of plasma is a strong and independent predictor for coronary artery disease in the Chinese Han population.Medicine (Baltimore) 2017, 96(37):e8058. https://doi.org/10.1097/ MD.0000000000008058. [PMID:28906400]

4. Ni W, Zhou Z, Liu T, Wang H, Deng J, Liu X, Xing G. Gender-and lesion number-dependent difference in "atherogenic index of plasma" in Chinese people with coronary heart disease.Sci Rep 2017, 7(1):13207. https://doi.org/ 10.1038/s41598-017-13267-6. [PMID: 29038593]

5. Lin XL, Xiao LL, Tang ZH, Jiang ZS, Liu MH. Role of PCSK9 in lipid metabolism and atherosclerosis. Biomed Pharmacother 2018, 104:36-44. https://doi.org/10.1016/j.biopha.2018.05.024. Review. [PMID:29758414].

6. Eslami SM, Nikfar S, Ghasemi M, Abdollahi M. Does Evolocumab, as a PCSK9 Inhibitor, Ameliorate the Lipid Profile in Familial Hypercholesterolemia Patients? A Meta-Analysis of Randomized Controlled Trials.J Pharm Pharm Sci 2017, 20:81-96. https://doi.org/10. 18433/J36C8N. [PMID: 28459663].

7. Cai G, Zhang B, Shi G, Weng W, Ma C, Song Y, Zhang J.The associations between proprotein convertase subtilisin/kexin type 9 E670G polymorphism and the risk of coronary artery disease and serum lipid levels: ameta-analysis. Lipids Health Dis 2015, 14:149. https://doi.org/10.1186/s12944-015-0154-7. [PMID:26576960]. 
8. $\quad$ Adi D, Xie X, Liu F, Ma YT, Abudoukelimu M, Wu Y, An Y, Yang YN, Li XM, Fu $Z Y$, Wang YT, Chen BD. Relationships between genetic polymorphisms of E670G in PCSK9 gene and coronary artery disease: a meta-analysis. Int J Clin Exp Med 2015, 8(8):13251-13258.[PMID:26550250].

9. Qiu C, Zeng P, Li X, Zhang Z, Pan B, Peng ZYF, Li Y, Ma Y, Leng Y, Chen R. What is the impact of PCSK9 rs505151 and rs11591147 polymorphisms on serum lipids level and cardiovascular risk: a metaanalysis.Lipids Health Dis 2017, 16(1):111. https://doi.org/10.1186/s12944017-0506-6. [PMID:28606094].

10. Mostaza JM, Lahoz C, Salinero-Fort MA, de Dios O, Castillo E, González-Alegre T, García-Iglesias F, Estirado E, Laguna F, Sabín C, López S, Cornejo V, de Burgos C, Sanchez V, Garcés C; Investigators of the SPREDIA-2 GroupR46L polymorphism in the PCSK9 gene: Relationship to lipid levels, subclinical vascular disease, and erectile dysfunction. J Clin Lipidol 2018 12(4): 1039-1046. https://doi.org/10.1016/j.jacl.2018.04.004. [PMID:29773421].

11. Jeenduang N, Porntadavity S, Wanmasae S. Combined PCSK9 and APOE polymorphisms are genetic risk factors associated with elevated plasma lipid levels in a Thai population. Lipids, 2015, 50(6): 543-553. https://doi.org/ 10.1007/s11745-015-4017-9. [PMID: 25899039].

12. Cai G, Zhang B, Ma C, Shi G, Weng W, Xue S. Associations of rs3744841 and rs3744843 polymorphisms in endothelial lipase gene with risk of coronary artery disease and lipid levels in a Chinese population. PLoS One 2016, 11(9): e0162727. [PMID: 27612170].

13. Cai G, He G, Qi C. The association between endothelial lipase -384A/C gene polymorphism and acute coronary syndrome in a Chinese population. Mol Biol Rep 2012, 39(11): 9879-9884. [PMID: 22723003].

14. Patel RS, Scopelliti EM, Olugbile O. The role of PCSK9 inhibitors in the treatment of hypercholesterolemia. Ann Pharmacother 2018: 1060028018771670. https://doi.org/10.1177/1060028018771670. [PMID: 29667842].

15. Bae KH, Kim SW, Choi YK, Seo JB, Kim N, Kim CY, Lee WK, Lee S, Kim JG, Lee IK, Lee JH, Park KG. Serum Levels of PCSK9 Are Associated with Coronary Angiographic Severity in Patients with Acute Coronary Syndrome.Diabetes Metab J 2018, 42(3): 207-214. https://doi.org/10.4093/dmj.2017.0081. [PMID: 29885102].

16. Burchardt P, Rzeźniczak J, Dudziak J, Dżumak A, Marchlewski T, GanowiczKaatz T, Popiak M, Słomczyński M, Jezierski M, Laskowski W, Łuczak T, Plewa R. Evaluation of plasma PCSK9 concentrations, transcript of LDL receptor, as well as the total number of monocyte LDL receptors in acute coronary syndrome patients.Cardiol J 2016, 23(6):604-609. https://doi.org/10.5603/CJ. a2016.0068. [PMID:27665855].

17. Leander K, Mälarstig A, Van't Hooft FM, Hyde C, Hellénius ML, Troutt JS, Konrad RJ, Öhrvik J, Hamsten A, de Faire U. Circulating Proprotein convertase Subtilisin/Kexin type 9 (PCSK9) predicts future risk of cardiovascular events independently of established risk factors. Circulation 2016, 133(13): 1230-1239. https://doi.org/10.1161/CIRCULATIONAHA.115. 018531. [PMID: 26896437].

18. Frohlich J, Dobiasova M. Fractional esterification rate of cholesterol and triglycerides to $\mathrm{HDL}$-cholesterol are powerful predictors of positive findings on coronary angiography. Clin Chem 2003, 4911: 1873-1880. [PMID: 14578319].

19. Wan H, Gumbiner B, Joh T, Riel T, Udata C, Forgues P, Garzone PD. Effects of Proprotein Convertase Subtilisin/Kexin Type 9 (PCSK9) Inhibition with Bococizumab on Lipoprotein Particles in Hypercholesterolemic Subjects. Clin Ther 2017, 39(11):2243-2259.e5. https://doi.org/10.1016/j.clinthera.2017. 09.009. [PMID: 29037448].

20. Tsai CW, North KE, Tin A, Haack K, Franceschini N, Saroja Voruganti V, Laston S, Zhang Y, Best LG, MacCluer JW, Beaty TH, Navas-Acien A, Kao WH, Howard BV. Both rare and common variants in PCSK9 influence plasma lowdensity lipoprotein cholesterol level in American Indians.J Clin Endocrinol Metab 2015, 100(2):E345-E349. https://doi.org/10.1210/jc.2014-3340. [PMID: 25412415].

21. Slimani A, Harira Y, Trabelsi I, Jomaa W, Maatouk F, Hamda KB, Slimane MN. Effect of E670G Polymorphism in PCSK9 Gene on the Risk and Severity of Coronary Heart Disease and Ischemic Stroke in a Tunisian Cohort.J Mol Neurosci 2014, 53(2):150-157. https://doi.org/10.1007/s12031-014-0238-2. [PMID: 24599757].

22. Hopewell JC, Malik R, Valdés-Márquez E, Worrall BB, Collins R; METASTROKE collaboration of the ISGC. Differential effects of PCSK9 variants on risk of coronary disease and ischaemic stroke.Eur Heart J 2018, 39(5):354-359. https://doi.org/10.1093/eurheartj/eh×373. [PMID: 29020353]
23. He XM, Chen L, Wang TS, Zhang YB, Luo JB, Feng XX. E670G polymorphism of PCSK9 gene of patients with coronary heart disease among Han population in Hainan and three provinces in the northeast of China.Asian Pac J Trop Med 2016, 9(2):172-176. https://doi.org/10.1016/j.apjtm.2016.01.008. [PMID: 26919950].

24. Hsu LA, Teng MS, Ko YL, Chang CJ, Wu S, Wang CL, Hu CF. The PCSK9 gene E670G polymorphism affects low-density lipoprotein cholesterol levels but is not a risk factor for coronary artery disease in ethnic Chinese in Taiwan. Clin Chem Lab Med, 2009, 47(2): 154-158. [PMID: 19191720].

25. Zhang N, Gao J, Liu Y, Sun G. Influence of PCSK9 gene E670G polymorphism on the risk of atherosclerotic coronary heart disease and plasma lipid level. Zhonghua Yi Xue Yi Chuan Xue Za Zhi 2017, 34(5):749-754. https://doi.org/10. 3760/cma.j.issn.1003-9406.2017.05.028. [PMID: 28981947].

26. Aung LH, Yin RX, Wu DF, Cao XL, Hu XJ, Miao L. Proprotein convertase subtilisin/kexin type 9 gene E670G polymorphism interacts with alcohol consumption to modulate serum lipid levels.Int J Med Sci 2013, 10(2):124-132. https://doi.org/10.7150/ijms.5296. [PMID: 2332988].

\section{Ready to submit your research? Choose BMC and benefit from:}

- fast, convenient online submission

- thorough peer review by experienced researchers in your field

- rapid publication on acceptance

- support for research data, including large and complex data types

- gold Open Access which fosters wider collaboration and increased citations

- maximum visibility for your research: over $100 \mathrm{M}$ website views per year

At BMC, research is always in progress.

Learn more biomedcentral.com/submissions 